\title{
Balance or Synergies between Environment and Economy-A Note on Model Structures
}

\author{
Sarah Wolf ${ }^{1, *}$, Franziska Schütze ${ }^{1}$ and Carlo C. Jaeger ${ }^{1,2}$ \\ 1 Global Climate Forum, Berlin 10178, Germany; franziska.schuetze@globalclimateforum.org (F.S.); \\ carlo.jaeger@globalclimateforum.org (C.C.J.) \\ 2 Academy of Disaster Reduction and Emergency Management (ADREM), Beijing Normal University, \\ Beijing 100875, China \\ * Correspondence: sarah.wolf@globalclimateforum.org; Tel.:+49-3020-6073-811
}

Academic Editors: Roberto Roson and S. Amer Ahmed

Received: 31 May 2016; Accepted: 28 July 2016 ; Published: 13 August 2016

\begin{abstract}
The UN sustainable development goals contain environmental, economic, and social objectives. They may only be reached, or at least it would be easier to reach them, if instead of a trade-off between these objectives that implies a need for balancing them, there are synergies to be reaped. This paper discusses how the structures of economic models typically used in policy analysis influence whether win-win strategies for the environment and the economy can be conceptualised and analysed. With a focus on climate policy modelling, the paper points out how, by construction, commonly used model structures find mitigation costs rather than benefits. This paper describes mechanisms that, when added to these model structures, can bring win-win options into a model's solution horizon, and which provide a spectrum of alternative modelling approaches that allow for the identification of such options.
\end{abstract}

Keywords: economic model structures and mechanisms; climate policy analysis models; win-win strategies; general equilibrium framework; multiple equilibria

\section{Introduction}

As pointed out by the editors of this special issue, careful examination of the complex economic, social, and environmental consequences of alternative policy options available is essential in working towards sustainability. In the past, economic modelling has played an important role in policy analysis. This paper discusses the importance of the key structures of the models used in these endeavours and describes how these structures may influence the results. It focuses on the example of climate policy analysis, where cost-benefit analyses have largely found a tradeoff between environmental and economic objectives, pointing to net economic costs of mitigating climate change [1].

Only rather recently, the possibility of win-win situations for climate and the economy [2], or co-benefits of climate policy [3], are also being discussed. In particular, in the context of the recent financial and economic crisis, climate policy is being considered as a driver of economic growth via the large investments that are needed for decarbonizing the economy $[4,5]$. The UN sustainable development goals (SDGs) include "no poverty", "zero hunger", "reduced inequalities", "decent work and economic growth", "climate action", and other environmental objectives. These particular goals relate to the concept of "green growth" with its environmental, economic, and social dimensions [6]. Identifying and seizing green growth strategies or win-win opportunities for both environmental and economic objectives would certainly facilitate, and may even be a prerequisite for, reaching the SDGs.

This paper discusses the structure of the most commonly used economic models for climate policy analysis and how they lead to results that yield net mitigation costs rather than benefits. It then outlines how climate policy analysis models can conceptualise win-win strategies for climate 
and the economy, both by considering a set of mechanisms that are not usually considered in these models, and by considering different modelling approaches. The paper is based on an earlier working paper that reviewed the literature of studies that can conceptualize green growth [7]; descriptions of the models themselves can be found there. The current paper's added value is to provide a concise categorization of mechanisms and model structures.

\section{Material and Methods}

In order to find mechanisms and modelling approaches that allow one to conceptualise and hence to carefully study win-win strategies for climate change mitigation policy, those works in the literature which find positive economic effects of climate policy were scrutinized. Hence, the "material" relied on here is a set of scientific papers, reports, working papers, and studies dominated by practice-oriented reports and studies rather than by scientific journal articles. The method of analysis applied is a rather informal one: model structures are extracted from model descriptions by reading the text and connecting the information to previous knowledge about model structures; descriptions of mechanisms represented in the models were also taken from these texts. As the purpose of this paper is to outline general structures, this depth of analysis was deemed sufficient here. Of course, each single model could be considered in much more detail. However, one could spend years on such a task. In many cases, the model documentations that are available are by no means sufficiently detailed for this, and while much could be learnt in this work, it would not necessarily add insight into the purpose of this particular paper.

\section{A Spectrum of Modelling Approaches}

Economic modelling plays an important role in policy analysis for sustainability (e.g., climate policy analysis). In order to analyse the effects of specific policy measures, the models are generally run to compare the results of a so-called business-as-usual (BAU) scenario (without the particular policy), with a scenario in which the policy is implemented. Comparing GDP growth, welfare, or similar criteria between the two scenarios then yields an assessment of the policy measure. For climate change mitigation, reductions of the chosen economic indicators' values in the mitigation scenario as compared with the BAU scenario are conceptualised as the cost of mitigation; increases are considered benefits.

This section outlines the conventional approach to climate policy analysis modelling, pointing to relevant structures that it inherits from general equilibrium economics (Section 3.1), and then it discusses mechanisms (Section 3.2) and modelling approaches (Section 3.3) that, going beyond the conventional climate policy model structure, allow for a possibility of win-win climate policy strategies. These mechanisms and structures result from an analysis of the material described above, where we consider both theoretical and computational modelling works which find net economic benefits of mitigation. While one needs computational models based on real-world data to assess the possible consequences of certain policies at a given place and time, we are also interested in theoretical models here, as computational models are based on given theoretical model structures. These represent the economy using some mechanisms and leaving out others. The mechanisms which are included may influence whether green growth is a possibility.

\subsection{The Most Common Approach for Modelling Climate Policy}

Most economic models used for climate policy analysis are grounded in the framework of general equilibrium theory. The central concept there is of course equilibrium, which, in economics, means market clearing; that is, aggregate supply balances aggregate demand. The qualifier "general" refers to the fact that all markets clear, as opposed to a partial equilibrium in a single market. Aggregate supply and demand in these markets arise from the individual supplies and demands of firms and households. These determine their supply or demand of good or labour by maximizing profits or utility (where households are assumed to have preferences that can be represented by 
a utility function that gives a higher utility value to the more preferred one of any two alternatives), taking prices as given. An important result from Arrow and Debreu [8] establishes the existence of a set of prices at which equilibrium is obtained (under certain technical conditions on utilities of households, production functions of firms, etc.). These prices are found by solving, simultaneously, a set of equations. Generally, the solution is not unique, so there are different possible equilibria, and there is no reason why one or another should prevail in a given economic system. This formalisation of economic systems does not provide mechanisms for their dynamics, or for which equilibrium is selected as the result (see, e.g., [9]).

As long as there are no externalities in the system (that is, actions of one agent influencing the utility or profit of another agent), equilibria are Pareto optimal; that is, no agent in the system can be made better off while all others stay at least at the same level.

The mathematical model formulated by Arrow and Debreu can account for several time steps by definining the same good to be different goods at different time steps. Two types of computational models that are very prominent in climate policy analysis are based on these ideas: computable general equilibrium (CGE) and optimal growth models (see, e.g., [10]). The focus of optimal growth models is the allocation of a produced good in each time step between consumption and investment in such a way that a representative household's lifetime utility—defined as an (infinite) sum of the discounted utilities derived from consumption at each time step-is maximized. This means the households in the general Arrow-Debreu model are all assumed to be identical, and, therefore, can be aggregated into one representative household. CGE models add an optimization of the allocation of resources to different sectors of the economy using input-output tables at each time step to a similar intertemporal optimization structure for capital. The assumption of representative agents reduces the number of possible equilibria to a single one in the general equilibrium framework. For a critique of the representative agent, see [11].

Using an optimization methodology with a single equilibrium, the business-as-usual scenario is, by definition, the single optimal outcome of the system when emissions are disregarded. To represent climate policy, emissions and their accumulation in the atmosphere are added into the model. Then, climate change mitigation policy enters as an additional constraint considered only for the mitigation scenario. This means that, by construction, the result can at most be as "good"-in terms of the indicators considered - as the BAU case. Under this approach, marginal changes induced by climate policy are studied within the given structure of the economic system. In this framework of marginal analysis, one typically finds mitigation costs rather than benefits.

The emerging green growth literature variously points out that given the current fossil fuel based economy, green growth requires a major structural transition of the economic system (e.g., [5,12,13]) that needs to go beyond the energy sector alone $[10,14]$. Since a transition to a different economic system structure cannot be represented within a marginal analysis, it is not surprising that the possibility of win-win strategies for climate policy is beyond the horizon of this modelling methodology.

\subsection{Mechanisms that Lead to Lower Cost (or Even Net Benefit) Estimates}

Various mechanisms have been discussed in the literature that may lead to net benefits from mitigating climate change. The aim of the present list is to briefly explain how they work:

- The external effect of emissions: Greenhouse gas emissions from production (e.g., of electricity) constitute a negative externality: producers of emissions do not take into account the effect these have on later generations through climate change. According to standard economic theory, externalities lead to suboptimal economic equilibria; in particular, activities related to a negative externality are generally overprovided. This implies that a Pareto improvement should be possible by internalizing the externality (see, e.g., [15], Chapter 11). Foley [16] presents a theoretical model to show that both present and future generations can be better off with mitigation if the current generation compensates its increased investment in mitigation technology by reducing conventional investment, rather than reducing consumption. This is 
because, according to the standard model logic, utility increases with consumption, and thus a reduction in consumption would imply a sacrifice.

See also [17-19] on this issue: Rezai and colleagues argue that the business-as-usual scenario commonly chosen as a reference is problematic. In the BAU case (an equilibrium of the economy with an externality), agents ignore the effects of their emissions. The competitive equilibrium diverges from the optimum because social costs of emitting are not taken into account. In the optimal case, agents are aware of these costs and choose the appropriate levels of mitigation. What is usually considered as BAU in the literature is labelled a "constrained optimal path" by Rezai and colleagues: agents know about the negative consequences of their emissions, but are constrained to "no mitigation". Their only means to avoid emissions is to accumulate less capital, which will then result in less production and therefore less emissions. The choice by current generations to invest less results in the corresponding choice to consume more, meaning that, compared with the mitigation scenario, consumption is higher in this scenario.

- Climate change damages: Mitigation cost estimates should ideally be derived from a businessas-usual case, with accurate climate change damage estimates and a mitigation scenario where these damages can be reduced or avoided. However, as such damage estimates are difficult or even impossible to obtain given long time scales and immense uncertainty, the mitigation scenario is often compared to a BAU scenario without damages caused by climate change. It is obvious that the mitigation scenario fares less well in the latter comparison, such that costs rather than benefits are more likely to be found. This point closely relates to the previous one. In both cases, future climate damages play a role. The perspective is a little different, though: accounting for an externality, the BAU case should not be assumed optimal. When accounting for climate damages, one can theoretically consider an optimal BAU scenario that can be expected to lead to a worse result with the inclusion of climate change damages than without, and may therefore also have a worse result than a mitigation scenario that avoids these damages (see [20,21] and references therein for a short sketch of the issue and available literature).

- Environment and natural resources: The environment and natural resources are often modelled only insofar as they are influenced by the economic system, but not explicitly as factors that, in turn, influence the economy. Introducing direct or indirect effects of the impact of the environment on economic activity may bring to light additional positive effects of environmental policy on the economic system [22-24]. Not only may the state of the environment itself be valued (in modelling terms, the state of the environment is an input to the utility function), increased environmental quality may also benefit the economic system-for example, if the positive effects of an improved environment on health lead to higher labour productivity [22]. For natural resources, the UNEP Green Economy Report provides examples of how environmental policy can lead to economic (among other) benefits [25]: Under business-as-usual, natural resource depletion and high energy costs lead to falling long-term growth rates, whereas natural resource use is mostly decoupled from economic growth for scenarios with additional green investments.

- Effects of environmental policy: Other than throught the enhancement of environmental quality that then influences the economic system, environmental policy itself can influence the economy positively or negatively $[22,23,25]$. Positive influences may occur by increasing market efficiency (correcting market failures, influencing behaviours, e.g., for energy efficiency), through a stimulus effect (green investments, e.g., for infrastructure) or via an innovation effect (driving investments into R\&D and innovation).

- Green investments take effect via different mechanisms in different sectors. While in the primary sectors (agriculture, fishing, forests, and water) investments in natural capital are directed towards restoring and maintaining ecosystem services as well as making management more sustainable and equitable, for secondary sectors such as energy, transport, and manufacturing, investments target opportunities for saving energy and resources [25].

- Technical change: The representation of technical change in models as exogenous, endogenous, or as induced by policy, and its implications for the assessment of mitigation costs has been widely 
discussed in the literature (see, $[20,26]$ for summaries and references therein for the literature). Let us emphasize here the mechanisms of learning-by-doing (e.g., $[27,28])$, and directed technical change [29]: Investment not only increases production via the direct effect of capital accumulation, but also via an indirect effect on producivity. Investments in green technologies can, therefore, increase technical change in green sectors, helping them to catch up with conventional technologies.

- Positive externalities from additional investment: There also is a positive externality involved in knowledge accumulation, and, hence, in technical change: Benefits of increasing productivity not only accrue to the investors themselves. If the social benefits of investment are not taken into consideration by single investors, as is often the case, market outcomes generally underprovide investment. Large investments are needed for decarbonizing the economy, and investment levels are currently low in most OECD countries. Hence, triggering additional investment (be it public, private, or a combination of these) is a mechanism that can make green growth feasible (e.g., [5,30]). In combination with other mechanisms, investment-oriented climate policy presents a green growth opportunity [31].

- Irrational behaviour and imperfect information: The behaviour of individual agents is represented as optimization under perfect foresight in general equilibrium style models. The inherent assumption in optimization approaches-that the reference scenario achieves the economic optimum-implies the assumption that all investment opportunities with a positive return are known and realized in the optimal scenario. Hence, following this model logic, there are no untapped investment opportunities, and any additional investments will be made at a net cost. If agents in a model may not know all investment opportunities, or if they behave suboptimally, negative cost options may result.

- Negative cost options: The literature indicates that a considerable amount of investments into GHG emission reductions can be realized at net negative costs (i.e., net benefits) [32]. Especially energy-efficiency investments, such as building insulation, lighting, air-conditioning, and more fuel-efficient vehicles, are reported as net negative abatement cost options. Increasing efficiency is, as mentioned above, recognized as one mechanism through which environmental policy can have positive economic effects [22].

- Financial market inefficiencies are another issue related to investments. The general equilibrium framework does not have money; prices are relative prices. Since all resources are optimally employed by assumption in the BAU case, as mentioned above, there are no untapped financial resources for additional investments, nor are there positive investment opportunities that are not funded in these models. When such inefficiencies are included in a model together with net negative cost investment opportunities, positive macroeconomic effects of mitigation measures can be found, as has been shown in [33-35].

- Expectation dynamics: Not only the individual behaviour of agents matters, but also their interaction in networks. The general equilibrium framework dispenses with these networks by construction: the market as a single central point for the exchange of goods makes networks between agents unnecessary. When solving a system of equations for those prices that balance aggregate supply and demand, the question of who trades with whom is never asked. Representing both the imperfect foresight of real-world agents via expectations and the fact that agents interact and may influence each other-considering the dynamics of expectations in networks of agents-is another mechanism that (in combination with other mechanisms) may lead to positive economic effects of climate policy [31,36].

\subsection{Model Structures that Lead to Lower Cost (or Even Net Benefit) Estimates}

Most of the mechanisms listed above can be found in one or another model from the literature that will be referenced in this section. However, the focus here is on broader model structures employed to assess climate and environmental policy. A graphical overview of what is presented in this section is given in Figure 1. 
The general structure of conventional climate policy analysis models has been outlined above: Rooted in the general equilibrium framework, computational models for climate policy assessments are mostly optimization models that consider a single equilibrium.

First, these models can be extended to bring the possibility of positive economic effects of mitigation within their horizon, while keeping the optimization and single equilibrium approach. A framework that uses several of the mechanisms listed above to extend an optimal growth model is presented by Hallegatte and colleagues [22,23], and a list of works that include environmental policies in growth models is reviewed by [24], with a focus on natural resource inputs and technical change.

Second, dropping the assumption of a single equilibrium, but keeping an optimization approach, the consideration of multiple equilibria may also allow for the identification of green growth strategies. If one dispenses with the assumption of a single equilibrium, the BAU equilibrium need no longer be optimal by assumption. It could be a local, but need not be the global optimum among one of several equilibria. Conceptualizing the current economic situation (the BAU case) and a green growth scenario as different equilibria opens room for the possibility of economic benefits from climate policy, if mitigation can shift the system to a better equilibrium. Such a shift goes beyond marginal changes and can be considered a structural transition deemed necessary for green growth, as mentioned before.

As a theoretical model example, a set of works on green growth by Zhang and colleagues [13,37-39] consider multiple equilibria in the form of different structures of specialisation and the division of labour. The underlying framework of inframarginal analysis generalizes the conventional framework of marginal analysis that focuses on resource allocation within a single one of these structures. By modelling mitigation policy as a driver of structural change in the division of labour, the inframarginal approach can acknowledge and analyse the possibility of green growth.

A computational example modifies a CGE-model for climate policy analysis to allow for the representation of several equilibria $[31,36]$. Combining the mechanisms of technical change, expectation dynamics, and investment-oriented climate policy listed above, these studies make a case for investment-oriented climate policy shifting the economic system from the current path to a green growth path. In other words, climate policies that increase total investment via a green investment impulse can yield both the long-term benefits of avoiding climate damages and the short-term benefits of moving from the current "bad equilibrium" [40] to a better one. Such policies can help to solve a coordination problem faced by investors-profits of individual investors depend on whether they correctly estimate growth prospects for the economy, but these prospects themselves depend on the expectations of the individual investors-by providing a credible green growth perspective.

Third, modelling approaches outside the general equilibrium framework relax both optimization and equilibrium assumptions. Examples are (macro)econometric models using a statistical approach for describing the economic system, and simulation models which represent relevant mechanisms on a computer to analyse the system behaviour based on model runs-e.g., with a focus on aggregate characteristics in system dynamics models or on the agents constituting the system in agent-based models.

An example of such a macroeconometric model is the E3ME model [41,42]. Its key characteristics include a non-optimal starting point and a non-equilibrium demand-led approach. This model includes the mechanism of irrational behaviour and imperfect information that leads to a possibility of net negative cost options, as mentioned above. Based on these model features, in this model's results, positive macroeconomic effects of mitigation measures are possible in the short term (e.g., [33-35]).

An example using a system dynamics model is the Green Economy Report by UNEP [25]: The Threshold21-World model [43] keeps track of both monetary and physical quantities to account for natural resource stocks. Mechanisms represented in this model relating to the influence of natural resources on the economic system have been listed above. 


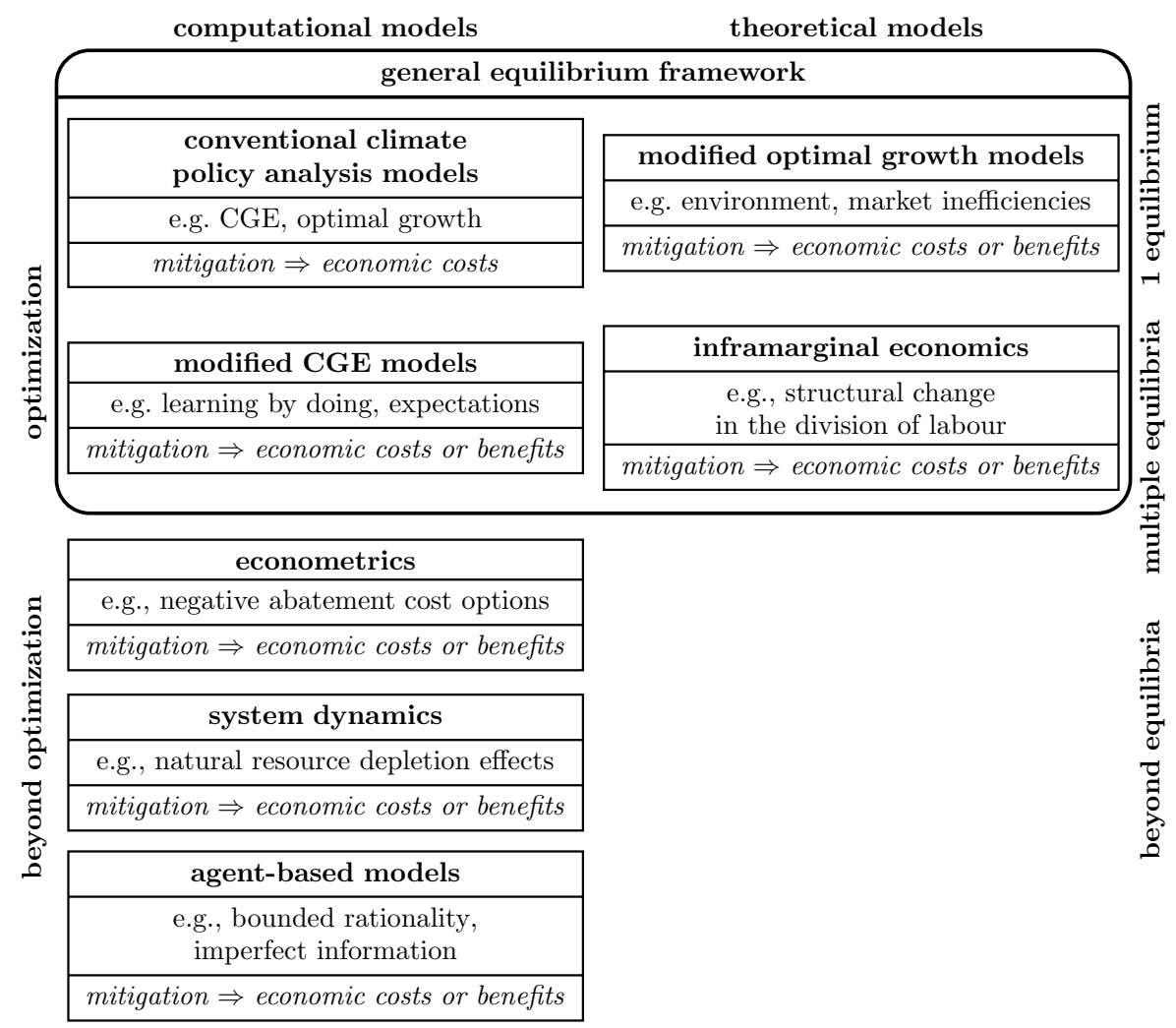

Figure 1. An overview of model structures with examples of mechanisms included.

Agent-based models (ABMs) are another type of simulation model that have been considered useful in the climate change context (e.g., [44,45]). However, examples of the use of macroeconomic agent-based models for climate policy analysis that find the possibility of green growth are preliminary $[31,46]$. There are ABMs for the analysis of climate policy at sectoral levels (e.g., in the field of electricity [47,48] and emissions trading [49]). By definition, ABMs can directly implement mechanisms relating to the representation of the agents. In particular, agents need not be omniscient optimizers of utility, but may be equipped with many kinds of decision rules.

Fourth, so-called "bottom-up" models usually describe mechanisms extracted from knowledge of the details of a system (e.g., a sector), independently from the concepts of optima and equilibria. As quite a bit has been written about the contrasts between conventional top-down climate policy analysis and sectoral bottom-up models, we skip this point here, referring the reader for example to $[20,26]$.

\section{Discussion}

Any modelling activity requires the choice of which elements of the real world system under consideration should be explicitly represented, and which ones left out of the model. Many more mechanisms could be discussed that could drive various outcomes in a complex system, and may have an influence on how well one can balance environmental and economic development goals, or whether there might even be synergies between them.

An important methodological question for the case of climate policy analysis lies in the assumption of an optimal BAU scenario. Suboptimality can be introduced in very condensed form (e.g., a single parameter representing the fraction of actual to potential output in production that accounts for market failures or inefficiencies, resulting from knowledge spillovers, behavioural biases, coordination failures, etc. [23]). It is a central point of multiple equilibria analysis that the BAU scenario can be a local optimum, but need not be the global one. Finally, non-optimization approaches, by construction, 
have the possibility of considering a non-optimal BAU case such that climate policy may lead to positive or negative overall economic effects.

Moreover, overall impacts can come as very different effects on different agents that make up the economic system. Fairness and distributional effects are not a typical focal point of macroeconomic climate policy assessments; they are, however, of utmost importance to the implementation of policies in real world economic systems, meaning that while certainly models should be built in the best possible way, building models is by no means enough. However, this is not for the present paper, where the focus is on structures in the models used.

\section{Conclusions and Outlook}

The present analysis has identified different ways of building models that can help to inform decision makers as to the possibilities of turning environmental challenges (in particular, the climate change challenge) into opportunities (in particular, green growth).

In further research into modelling for assessing the costs or benefits of environmental policy, there is scope for including the mechanisms discussed into models and incorporating theoretical model extensions of standard models that have already been done into conventionally applied (that is, computational) climate policy analysis models.

Further, there is scope for considering multiple equilibria and for modelling approaches that do not assume optimization and equilibrium concepts. Within a general equilibrium view (but outside the standard marginal modelling approach that considers a single equilibrium), the current economic situation and one of green growth can be conceptualized as two different equilibria. Further research into the dynamics of equilibrium transitions could focus on expectation and convention dynamics, as well as social habit diffusion in complex systems of heterogenous agents. For example, self-fulfilling dynamics arising from feedbacks between agents' expectations may play a role. Therefore, how these can be modelled within a macroeconomic setting deserves further research. Efforts in this direction certainly go beyond the general equilibrium framework, tying together evolutionary game theory, complex networks, and agent-based modelling (among possibly other fields) to describe iterated games between agents in complex networks.

Acknowledgments: The authors would like to thank Steffen Fürst, Jochen Hinkel, Andreas Ligtvoet, Jahel Mielke, Hector Pollitt, Rich Rosen, Gesine Steudle, and Joan David Tàbara for very helpful discussions and comments on earlier versions of the paper. Financial support by the EU projects SIMPOL (Grant 610704), Symphony (Grant 611875), and CoeGSS (Grant 676547), as well as by the German Federal Ministry for the Environment, Nature Conservation, Building and Nuclear Safety under Grant 03KSE041 (Bewertungsmodul Klimapolitik) is gratefully acknowledged. Open access publication was supported by SIMPOL.

Author Contributions: Carlo C. Jaeger initiated the analysis, that was performed by all three authors together; Sarah Wolf wrote the paper with contributions from the other two authors.

Conflicts of Interest: The authors declare no conflict of interest.

\section{Abbreviations}

The following abbreviations are used in this manuscript:

$\begin{array}{ll}\text { BAU } & \text { business as usual } \\ \text { GCD } & \text { gross domestic product } \\ \text { CGE } & \text { computable general equilibrium } \\ \text { UNEP } & \text { United Nations Environment Programme } \\ \text { R\&D } & \text { research and development } \\ \text { OECD } & \text { Organisation for Economic Co-operation and Development } \\ \text { GHG } & \text { greenhouse gas } \\ \text { ABM } & \text { agent-based model }\end{array}$




\section{References}

1. IPCC. Climate change 2014: Mitigation of climate change. In Contribution of Working Group III to the Fifth Assessment Report of the Intergovernmental Panel on Climate Change; Cambridge University Press: Cambridge, UK; New York, NY, USA, 2014.

2. Jaeger, C.C.; Hasselmann, K.; Leipold, G.; Mangalagiu, D.; Tábara, J.D. Reframing the Problem of Climate Change: From Zero Sum Game to Win-Win Solutions; Routledge: Oxford, UK, 2012.

3. Edenhofer, O.; Jakob, M.; Creutzig, F.; Flachsland, C.; Fuss, S.; Kowarscha, M.; Lessmann, K.; Mattaucha, L.; Siegmeier, J.; Steckel, J.C. Closing the emission price gap. Glob. Environ. Chang. 2015, 31, 132-143.

4. The Global Commission on the Economy and Climate. Better Growth, Better Climate: The New Climate Economy Report, Synthesis Report. Available online: http://newclimateeconomy.report/ (accessed on 4 August 2016).

5. Romani, M.; Stern, N.; Zenghelis, D. The Basic Economics of Low-Carbon Growth in the UK; Policy Brief; Grantham Research Institute on Climate Change and the Environment and Centre for Climate Change Economics and Policy: London, UK, 2011.

6. Organisation for Economic Co-operation and Development (OECD). Towards Green Growth; Organisation for Economic Co-operation and Development: Paris, France, 2011.

7. Wolf, S.; Schütze, F.; Jaeger, C.C. The Possibility of Green Growth in Climate Policy Analysis Models-A Survey; GCF Working Paper; Global Climate Forum: Berlin, Germany, 2016.

8. Arrow, K.J.; Debreu, G. Existence of an equilibrium for a competitive economy. Econometrica 1954, 22, $265-290$.

9. Saari, D. Mathematical complexity of simple economics. Not. AMS 1995, 42, 222-230.

10. Bowen, A.; Campiglio, E.; Tavoni, M. A macroeconomic perspective on climate change mitigation: Meeting the financing challenge. Clim. Chang. Econ. 2014, doi:10.1142/S2010007814400053.

11. Kirman, A.P. Whom or what does the representative individual represent? J. Econ. Perspect. 1992, 6, 117-136.

12. Hepburn, C.; Bowen, A. Prosperity with growth: Economic growth, climate change and environmental limits. In Handbook on Energy and Climate Change; Edward Elgar Publishing: Cheltenham, UK, 2013.

13. Zhang, Y. Climate change and green growth: A perspective of division of labor. China World Econ. 2014, 22, 93-116.

14. Zysman, J.; Huberty, M. Religion and reality in the search for green growth. Intereconomics 2012, 3, 140-146.

15. Mas-Colell, A.; Whinston, M.D.; Green, J.R. Microeconomic Theory; Oxford University Press: New York, NY, USA, 1995.

16. Foley, D. The economic fundamentals of global warming. In Twenty-First Century Macroeconomics: Responding to the Climate Challenge; Harris, J., Goodwin, N., Eds.; Edward Elgar Publishing: Cheltenham/Northampton, UK, 2009.

17. Rezai, A.; Foley, D.K.; Taylor, L. Global warming and economic externalities. Econ. Theory 2012, 49, 329-351.

18. Rezai, A. The opportunity cost of climate policy: A question of reference. Scand. J. Econ. 2011, 113, 885-903.

19. Rezai, A. Recast the DICE and its policy recommendations. Macroecon. Dyn. 2010, 14, 275-289.

20. Rosen, R.A.; Guenther, E. The economics of mitigating climate change: What can we know? Technol. Forecast. Soc. Chang. 2015, 91, 93-106.

21. Rosen, R.A. Is the IPCC's 5th Assessment a denier of possible macroeconomic benefits from mitigating climate change? Clim. Chang. Econ. 2016, doi:10.1142/S2010007816400030.

22. Hallegatte, S.; Heal, G.; Fay, M.; Treguer, D. From Growth to Green Growth-A Framework. Available online: http://www.nber.org/papers/w17841.pdf (accessed on 4 August 2016).

23. The World Bank. Inclusive Green Growth. Available online: http://siteresources.worldbank.org/ EXTSDNET/Resources/Inclusive_Green_Growth_May_2012.pdf (accessed on 4 August 2016).

24. Withagen, C.; Smulders, S. Green Growth. Lessons from Growth Theory. Available online: http://documents. worldbank.org/curated/en/380011468340178901/pdf/wps6230.pdf (accessed on 4 August 2016).

25. United Nations Environment Programme. Towards a Green Economy: Pathways to Sustainable Development and Poverty Eradication; United Nations Enviroment Programme: Nairobi, Kenya, 2011.

26. Scrieciu, S.; Rezai, A.; Mechler, R. On the economic foundations of green growth discourses: The case of climate change mitigation and macroeconomic dynamics in economic modeling. WIREs Energy Environ. 2013, 2, 251-268. 
27. Frankel, M. The production function in allocation and growth: A synthesis. Am. Econ. Rev. 1962, 52, 996-1022.

28. Lucas, R. On the mechanics of economic development. J. Monet. Econ. 1988, 22, 3-42.

29. Acemoglu, D.; Aghion, P.; Bursztyn, L.; Hemous, D. The environment and directed technical change. Am. Econ. Rev. 2012, 102, 131-166.

30. Bowen, A.; Fankhauser, S.; Stern, N.; Zenghelis, D. An Outline of the Case for a 'Green' Stimulus. Avilable online: http://eprints.lse.ac.uk/24345/1/An_outline_of_the_case_for_a_green_stimulus.pdf (accessed on 4 August 2016).

31. Jaeger, C.C.; Schütze, F.; Fürst, S.; Mangalagiu, D.; Meißner, F.; Mielke, J.; Steudle, G.A.; Wolf, S. Investment-Oriented Climate Policy—An Opportunity for Europe; Global Climate Forum: Berlin, Germany, 2015.

32. McKinsey \& Company. Impact of the Financial Crisis on Carbon Economics; McKinsey \& Company: New York, NY, USA, 2010.

33. European Commission. Impact Assessment Accompanying the Document Directive of the European Parliament and of the Council on Energy Efficiency and Amending and Subsequently Repealing Directives 2004/8/EC and 2006/32/EC; Commission Staff Working Paper; SEC: Washington, DC, USA, 2011.

34. Sijm, J.; Boonekamp, P.; Summerton, P.; Pollitt, H.; Billington, S. Investing EU ETS Auction Revenues into Energy Savings. Available online: http://www.ecn.nl/docs/library/report/2013/e13033.pdf (accessed on 4 August 2016).

35. Jobs, Growth and Warmer Homes. Evaluating the Economic Stimulus of Investing in Energy Efficiency Measures in Fuel Poor Homes. Available online: https://www.e3g.org/docs/Jobs-growth-and-warmerhomes_Executive_Summary.pdf (accessed on 4 August 2016).

36. Jaeger, C.C.; Paroussos, L.; Mangalagiu, D.; Kupers, R.; Mandel, A.; Tábara, J.D. A New Growth Path for Europe-Generating Prosperity and Jobs in the Low-Carbon Economy; Synthesis Report; Commissioned by the Federal Ministry for the Environment, Nature Conservation and Nuclear Safety; Global Climate Forum: Berlin, Germany, 2011.

37. Shi, H.; Zhang, Y. How Could Mitigations Promote Economic Progress: A Theoretical Framework; Working Paper; Climate Change and Green Growth Project Development Research Centre of the State Council (DRC): Beijing, China, 2012.

38. Zhang, Y.; Shi, H. From burden-sharing to opportunity-sharing: Unlocking the climate negotiations. Clim. Policy 2014, 14, 63-81.

39. Zhang, Y. Can China Achieve Green Growth? In China: A New Model for Growth and Development; Garnaut, R., Fang, C., Song, L., Eds.; ANU E Press, The Australian National University: Canberra, Australia, 2013.

40. Introductory Statement to the Press Conference (with Q\&A). Available online: https://www.ecb.europa.eu/ press/pressconf/2016/html/is160721.en.html (accessed on 4 August 2016).

41. Cambridge Econometrics. E3ME Technical Manual, version 6.0; Cambridge Econometrics: Cambridge, UK, 2014.

42. Cambridge Econometrics. Available online: http://www.camecon.com/Home.aspx (accessed on 4 August 2016).

43. Millennium Institute. Available online: http://www.millennium-institute.org/integrated_planning/tools/ T21/ (accessed on 4 August 2016).

44. Moss, S.; Pahl-Wostl, C.; Downing, T. Agent-based integrated assessment modelling: The example of climate change. Integr. Assess. 2001, 2, 17-30.

45. Giupponi, C.; Borsuk, M.E.; de Vries, B.J.; Hasselmann, K. Innovative approaches to integrated global change modelling. Environ. Model. Softw. 2013, 44,1-9.

46. Jaeger, C.C.; Fürst, S.; Mielke, J.; Schütze, F.; Steudle, G.A.; Wolf, S. STOEMSys—Towards a Sustainability Transition Open Economic Modelling System; Final Report; Global Climate Forum: Berlin, Germany, 2015.

47. Reeg, M.; Nienhaus, K.; Roloff, N.; Pfenning, U.; Deissenroth, M.; Wassermann, S.; Hauser, W.; Weimer-Jehle, W.; Kast, T.; Klann, U. Weiterentwicklung Eines Agentenbasierten Simulationsmodells (AMIRIS) zur Untersuchung des Akteursverhaltens bei der Marktintegration von Strom aus Erneuerbaren Energien unter Verschiedenen Fördermechanismen; DLR, ZIRIUS, Thomas Kast Simulation Solutions, IZES, Stuttgart, Vilshofen, Saarbrücken, 2013. Available online: http://www.dlr.de/tt/Portaldata/41/Resources/ dokumente/institut/system/publications/AMIRIS_Weiterentwicklung_Abschlussbericht.pdf (accessed on 4 August 2016). (In German) 
48. Chappin, E.; Dijkema, G. Agent-based modelling of energy infrastructure transitions. Int. J. Crit. Infrastruct. 2010, 6, 106-130.

49. Zhang, B.; Zhang, Y.; Bi, J. An adaptive agent-based modeling approach for analyzing the influence of transaction costs on emissions trading markets. Environ. Model. Softw. 2011, 26, 482-491.

(c) 2016 by the authors; licensee MDPI, Basel, Switzerland. This article is an open access article distributed under the terms and conditions of the Creative Commons Attribution (CC-BY) license (http:/ / creativecommons.org/licenses/by/4.0/). 